\title{
An investigation on alkali-activated slag pastes containing quartz powder subjected to elevated temperatures
}

\author{
Alaa M. Rashad (Main and Corresponding Author) \\ Building Materials Research and Quality Control Institute \\ Housing \& Building National Research Center (HBRC) \\ 1770 Cairo (Egypt) \\ Department of Civil Engineering, College of Engineering, Shaqra University (Saudi Arabia) \\ alaarashad@yahoo.com
}

Manuscript Code: 1455

Date of Acceptance/Reception: 24.01.2020/30.04.2019

DOI: 10.7764/RDLC.19.1.42-51

\begin{abstract}
In this work, the opportunity of employing crystalline silica in the form of quartz powder (QP) to increase the fire resistance of alkali-activated slag (AAS) has been explored. The ground granulated blast-furnace slag (designated as slag) was partially replaced with QP at levels changed from $5 \%$ to $30 \%$ with a step of $5 \%$, by weight. After curing for 28 days, the specimens were subjected to elevated temperatures varying from $400{ }^{\circ} \mathrm{C}$ to $1000{ }^{\circ} \mathrm{C}$ with a step of $200{ }^{\circ} \mathrm{C}$ for $2 \mathrm{~h}$. The compressive strength before and after heating was measured. The new formed phases were evaluated by using $\mathrm{X}$ ray diffraction (XRD), whilst the decomposition phases were evaluated by using thermogravimetric (TGA). The changes in the microstructures were monitored by using scanning electron microscopy (SEM). The results showed a positive effect of incorporation of QP, up to $30 \%$, in AAS system before and after exposure to elevated temperatures.
\end{abstract}

Keywords: Alkali-activated slag, Quartz powder, Elevated temperatures, residual compressive strength.

As known the production of PC consumes a high amount of virgin raw materials such as limestone and sand, consumes intensive energy and emits a lot of $\mathrm{CO}_{2}, \mathrm{NO}_{x}$ and $\mathrm{SO}_{2}$. In addition, the binders based on PC suffer from low durability and resistance to elevated temperatures. The world Business Council for Sustainable Development (WBCSD) and the International Energy Agency (IEA) indicate that the recent tendency in the use and provision of energy is not green, economic and sustainable for societies and therefore, they have established a course for the substitution of the recent energy system with low carbon energy technologies to decrease carbon dioxide emissions by half in cement industry by 2050 (Davidovits, 1994). Therefore, it is better to use more friendly binder materials such as blended cement and alkali-activated materials. Cement blended with by-products such as slag and FA, especially in large amounts, can be used to mitigate some problems associated with the production of PC as well as the durability of the matrices manufactured from neat PC (Rashad, 2018b). Another choice is to replace cement with alkali-activated materials. Alkali-activated binders are more effective than PC ones in mechanical strength, fire resistance and durability. The used source materials for alkali-activations are either by-products such as slag, rice-husk ash and FA or natural materials such as metakaolin (MK) or clay. The incorporation of alkali-activated materials not only have superior properties over PC one, but also have an effective methodology for waste management targets, of which a huge amounts of slag, FA and rice-husk ash can be used.

Over the last few decades, a lot of researches and developments on alkali-activated material technology have been carried out globally aiming to endorse this system as a sustainable building material for the future. Alkali-activated materials can be considered as a promising green binder and building materials in the $21^{\text {st }}$ century. The applications of these materials are grown rapidly especially for durability and fire resistance. The incorporation of slag as a source material for alkali activation has many benefits over other sources as follows: do not require calcination compared to other sources such as kaolin and rice-husk ash; AAS, in most cases, do not require heat for curing compared to other sources such as FA and MK, lower amount of activators are required for activation. In spite of AAS system has good properties and fire resistance, there are several attempts to produce AAS binder with more modified properties and fire resistance by partially replacing slag with other materials.

Rashad (2015) partially replaced slag in AAS pastes activated with $\mathrm{Na}_{2} \mathrm{SO}_{4}$ by $5 \% \mathrm{SF}$, FA, limestone powder, hydrated lime or PC. The results showed that the incorporation of limestone powder exhibited the highest workability, whilst the incorporation of SF exhibited the highest compressive strength. The incorporation of PC or FA or limestone can reduce the drying shrinkage. Rashad, Bai, Basheer, Collier, \& Milestone (2012) found higher compressive strength before and after exposure to elevated temperatures of AAS activated with $\mathrm{Na}_{2} \mathrm{SO}_{4}$ by increasing the fineness of slag. Rashad, Zeedan, \& Hassan (2016) found higher residual compressive strength of AAS pastes activated with sodium 
silicate after exposure to $200-1000{ }^{\circ} \mathrm{C}$ by increasing the concentration of $\mathrm{Na}_{2} \mathrm{O}$ from $3.5 \%$ to $5.5 \%$ and $6.5 \%$, whilst increasing activator concentration up to $10.5 \%$ led to adverse effect. Pan, Tao, Cao, Wuhrer, \& Murphy (2018) found higher residual compressive strength of AAS pastes by partially replacing slag with $50 \%$ and $90 \%$ FA after exposure to 300 and $600{ }^{\circ} \mathrm{C}$. Vaičiukynienè, Nizevičienè, Kielè, Janavičius, \& Pupeikis (2018) found higher residual compressive strength of AAS pastes by partially replaced slag with $5 \%$ phosphogypsum after exposure to 400,600 and $800{ }^{\circ} \mathrm{C}$.

From the previous review, it can be observed that there are limited studies concerning with the behavior of AAS pastes blended with other materials after being subjected to elevated temperatures. In that respect, the behavior of AAS pastes blended with QP under the impact of elevated temperatures up to $1000{ }^{\circ} \mathrm{C}$ has not yet been investigated up to now. For that reason, the main goal of this investigation is to study the performance of AAS pastes comprising different levels of QP after exposure to elevated temperatures. Slag was partially replaced with QP at levels changed from $5 \%$ to $30 \%$ with a step of $5 \%$, by weight. After curing up to 28 days, the specimens were exposed to different elevated temperatures starting from $400{ }^{\circ} \mathrm{C}$ up to $1000{ }^{\circ} \mathrm{C}$ with a step of $200{ }^{\circ} \mathrm{C}$ for $2 \mathrm{~h}$. The formed decomposition phases were identified with X-ray diffraction (XRD) and thermogravimetric (TGA), whilst the microstructure of the selected samples was monitored by scanning electron microscopy (SEM).

\section{Materials}

Methodology

Slag used as a source material for alkali activation. It was delivered in the form of water quenched fine grain from the disposal waste of Helwan steel factory (in Cairo-Egypt). The slag was then finely ground in a laboratory ball mill to reach a Blaine surface area of $300 \mathrm{~m}^{2} / \mathrm{kg}$. The QP was brought from the Egyptian Company for Manufacturing Electrical Insulators. The specific weight and bulk density of the slag were 2.46 and $1.04 \mathrm{~g} / \mathrm{cm}^{3}$, respectively. Table 1 shows the sieve analysis of the QP. The relevant chemical composition of slag and QP was evaluated by X-ray fluorescence (XRF) spectrometry and the results are given in Table 2. Figure 1 shows the diffract-grams of the raw slag and QP samples analyzed by XRD. Liquid sodium silicate which had a density of $1.38 \mathrm{~g} / \mathrm{cm}^{3}$ and a composition of $27 \%$ $\mathrm{SiO}_{2}, 8.2 \% \mathrm{Na}_{2} \mathrm{O}$ and $64 \% \mathrm{H}_{2} \mathrm{O}$ was used as an alkaline activator.

Table 1. Sieve analysis of QP. Source: Self-Elaboration.

\begin{tabular}{lcc}
\multicolumn{3}{c}{ Table 1. Sieve analysis of QP. Source: Self-Elaboration. } \\
\hline Residue on sieve \% & Particle size distribution \\
\hline $90 \mu \mathrm{m}<=1$ & $>90 \mu \mathrm{m}$ & 1 \\
$63 \mu \mathrm{m} \mathrm{2-4}$ & $63-90 \mu \mathrm{m}$ & $1-3$ \\
$45 \mu \mathrm{m} \mathrm{7-10}$ & $45-63 \mu \mathrm{m}$ & $5-6$ \\
$32 \mu \mathrm{m} \mathrm{15-20}$ & $32-45 \mu \mathrm{m}$ & $8-10$ \\
& $<32 \mu \mathrm{m}$ & $80-85$ \\
\hline
\end{tabular}

Table 2. Chemical composition of the starting materials. Source: Self-Elaboration.

\begin{tabular}{lcc}
\hline Oxide Composition & Slag (\%) & QP (\%) \\
\hline $\mathrm{SiO}_{2}$ & 36.95 & 98.81 \\
$\mathrm{Al}_{2} \mathrm{O}_{3}$ & 10.01 & 0.14 \\
$\mathrm{Fe}_{2} \mathrm{O}_{3}$ & 1.48 & 0.05 \\
$\mathrm{CaO}$ & 33.07 & 0.51 \\
$\mathrm{MgO}$ & 6.43 & 0.02 \\
$\mathrm{Na}_{2} \mathrm{O}$ & 1.39 & 0.04 \\
$\mathrm{~K}_{2} \mathrm{O}$ & 0.74 & 0.03 \\
$\mathrm{SO}_{3}$ & 3.52 & 0.03 \\
$\mathrm{TiO}_{2}$ & 0.52 & 0.02 \\
$\mathrm{P}_{2} \mathrm{O}_{5}$ & 0.1 & 0.32 \\
$\mathrm{MnO}^{-}$ & 0.52 & - \\
$\mathrm{Cl}^{-}$ & 0.05 & - \\
L.O.I. & 0 & 0.32 \\
\hline
\end{tabular}

\section{Mixture preparations}

Seven alkali-activated mixtures were prepared. The first one comprised of plain AAS (without any addition of QP). The other six mixtures were prepared by partially substituting slag with QP at levels ranging from $5 \%$ to $30 \%$, by weight, with a step of $5 \%$. A fixed concentration of sodium silicate with a dosage of $25 \%$ from total powder weight was employed to activate each mixture. A fixed dosage of $\mathrm{w} / \mathrm{b}$ ratio of 0.15 was used for all mixtures. Table 3 shows the details of the different mixture proportions. 
Figure 1. XRD patterns for raw slag (a) and QP (b). Source: Self-Elaboration.

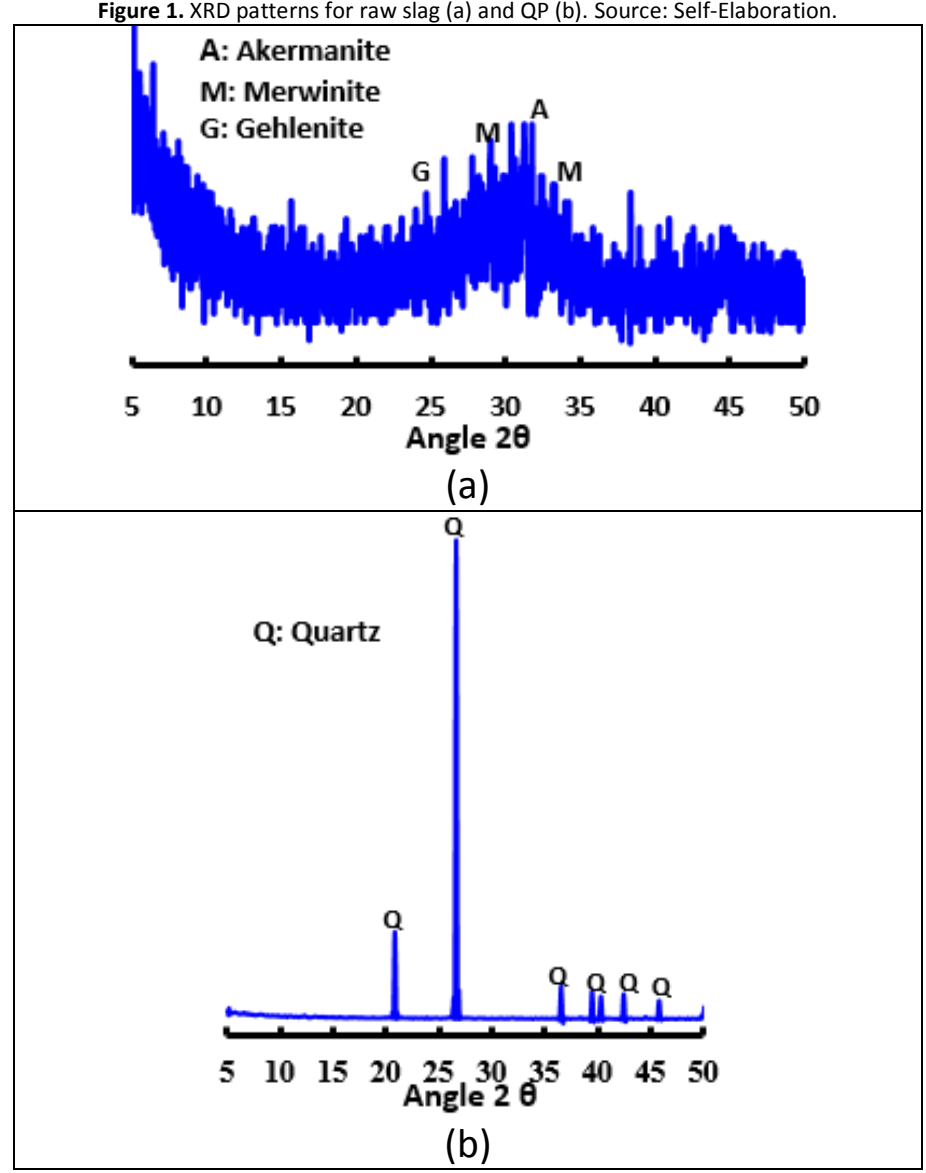

\begin{tabular}{ccc}
\multicolumn{3}{c}{ Table 3. Details of paste mix proportions. Source: Self-Elaboration } \\
\hline Mixture & Slag (\%) & QP (\%) \\
\hline QP0 & 100 & 0 \\
QP5 & 95 & 5 \\
QP10 & 90 & 10 \\
QP15 & 85 & 15 \\
QP20 & 80 & 20 \\
QP25 & 75 & 25 \\
QP30 & 70 & 30 \\
\hline
\end{tabular}

\section{Methods}

The slag/QP with proportions of $100 \% / 0 \%, 95 \% / 5 \%, 90 \% / 10 \%, 85 \% / 15 \%, 80 \% / 20 \%, 75 \% / 25 \%$ and $70 \% / 30 \%$, by weight, were mixed together. The mixing period was $2 \mathrm{~min}$, followed by 2 min resting period and a further 2 min mixing in a mechanical mixture with a working speed of $80 \mathrm{rpm}$. The water and sodium silicate solution was then added and mixing commenced following the same mixing time procedure. After complete mixing, the paste was placed into $20 \times 20 \times 20 \mathrm{~mm}$ moulds which were vibrated on a special vibrator table for 1 min to remove any air bubble. The fresh samples were covered with a polyethylene sheet to prevent evaporations. The samples were removed from the moulds after $24 \mathrm{~h}$ from casting. Then they were cured in lab air at room temperature up to testing date.

At the ages of 7 and 28 days, four cubes per paste mixture were tested for the compressive strength according to ASTM C109/C109 M-16a and the average value was determined. After curing for 28 days, sixteen cubes per mixture were transferred to an electrical oven for drying at $105 \pm 1{ }^{\circ} \mathrm{C}$ for $24 \mathrm{~h}$ to remove moisture and eliminate spalling. After drying, the cubes were placed into a special electrical furnace, of which the temperature was increased to the required temperature regimes of $400,600,800$ and $1000{ }^{\circ} \mathrm{C}$ at a heating rate of $6{ }^{\circ} \mathrm{C} / \mathrm{min}$ and held at each temperature degree for $2 \mathrm{~h}$. After exposure to each elevated temperature, the cubes were left inside the furnace to 
cool gradually to room temperature to avoid any temperature shock. The cubes then brought out from the furnace and tested in compression to determine the unstressed residual compressive strength.

After the compression test at the age of 28 days and after exposure to elevated temperatures, selected fragments from the crushed samples were stored in acetone for three days to stop the hydration. The fragments were then filtered from the acetone and dried under vacuum in desiccators. A part of the dried samples was ground in an agate mortar. Particles passing a $63 \mu \mathrm{m}$ sieve were used for the XRD and TGA. Selected pieces were also used for the SEM investigation.

\section{Compressive strength}

Results and discussion

The compressive strength of the hardened pastes was determined at the ages of 7 and 28 days. As shown in Figure 2 , the compressive strength of the studied hardened pastes gradually increased by replacing a portion of slag with QP at different levels. The compressive strength increased with increasing QP content from $0 \%$ to $30 \%$ with an increment of $5 \%$. Comparing the compressive strength results, it can be noted that the pastes of QP30 that including $30 \%$ QP coupled with $70 \%$ slag exhibited the highest compressive strength amongst all mixtures, whilst the pastes of QP0 that containing $100 \%$ slag exhibited the lowest compressive strength. The compressive strength at age of 7 days was enhanced by $2.1 \%, 12.8 \%, 18.1 \% 31.2 \%, 39.3 \%$ and $49.2 \%$ with the incorporation of $5 \%, 10 \%, 15 \%, 20 \%, 25 \%$ and $30 \%$ QP, respectively, whilst the 28 days compressive strength was enhanced by $4.1 \%, 18.1 \%, 30.1 \%, 47.4 \%, 73.5 \%$ and $97.3 \%$, respectively.

The enhancement in the compressive strength with including QP could be related to the packing effect of the crystalline fine QP particles that acted as fillers. These particles can fill the space inside the skeleton of the hardened microstructure of the pastes. Therefore, the denser structure was produced as will be shown in the microstructural analysis section. Consequently, the compressive strength was enhanced. In addition, the fine particles of QP can cause a significant improvement in the distribution of pore size and pore shape of the microstructure, of which the pore distribution is one of the major factors affecting strength development (Nguyen et al., 2019). The incorporation of QP not only improves the compressive strength of AAS system but also improves the compressive strength of the traditional cement system (Rashad, 2018a).

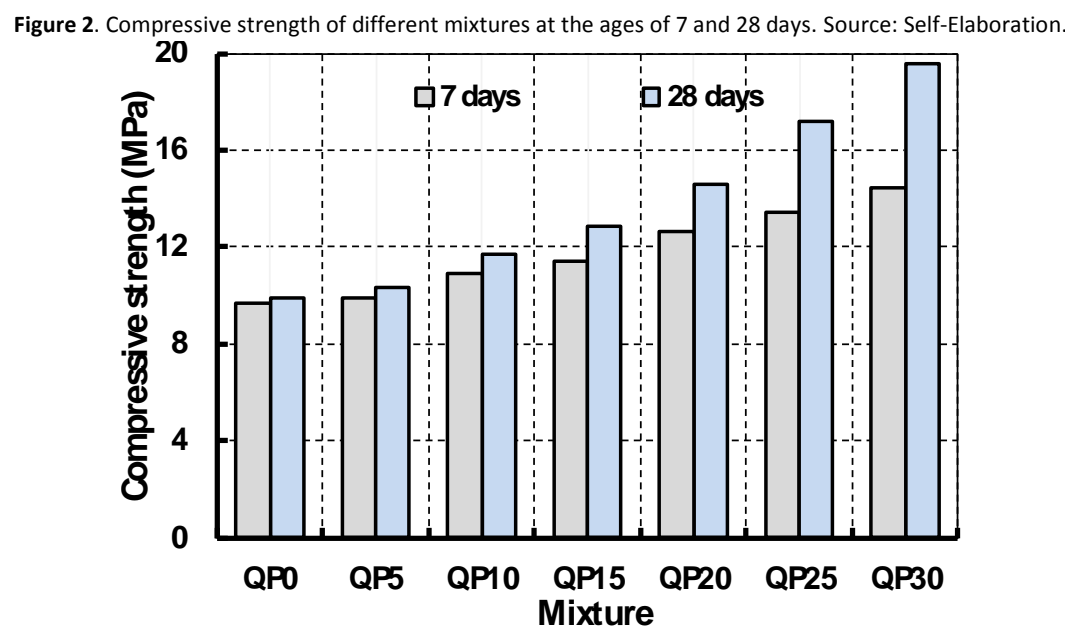

\section{The response of hardened paste mixtures to elevated temperatures}

The residual compressive strength of each investigated AAS paste mixture after subjecting to elevated temperatures was compared with its reference which was crushed at the age of 28 days without subjecting to elevated temperatures. The residual compressive strength values of the mixtures containing QP after subjecting to elevated temperatures were compared with their counterparts of the pure AAS pastes. Figure 3 presents the disparity of compressive strength of different pastes with elevated temperatures. After exposure to 400 and $600{ }^{\circ} \mathrm{C}$, no obvious change in the initial compressive strength of the pure AAS pastes was noted. On the other hand, a noticeable change in the compressive strength was observed after exposure to 800 and $1000^{\circ} \mathrm{C}$. The residual compressive strength was significantly enhanced after exposure to 800 and $1000{ }^{\circ} \mathrm{C}$. The residual compressive strength was increased with increasing temperature degrees from $600{ }^{\circ} \mathrm{C}$ to $800{ }^{\circ} \mathrm{C}$ and from $800{ }^{\circ} \mathrm{C}$ to $1000^{\circ} \mathrm{C}$. The residual compressive strength 
at $800{ }^{\circ} \mathrm{C}$ reached approximately 2.95 times greater than the reference, whilst it reached approximately 3.15 times greater after exposure to $1000^{\circ} \mathrm{C}$.

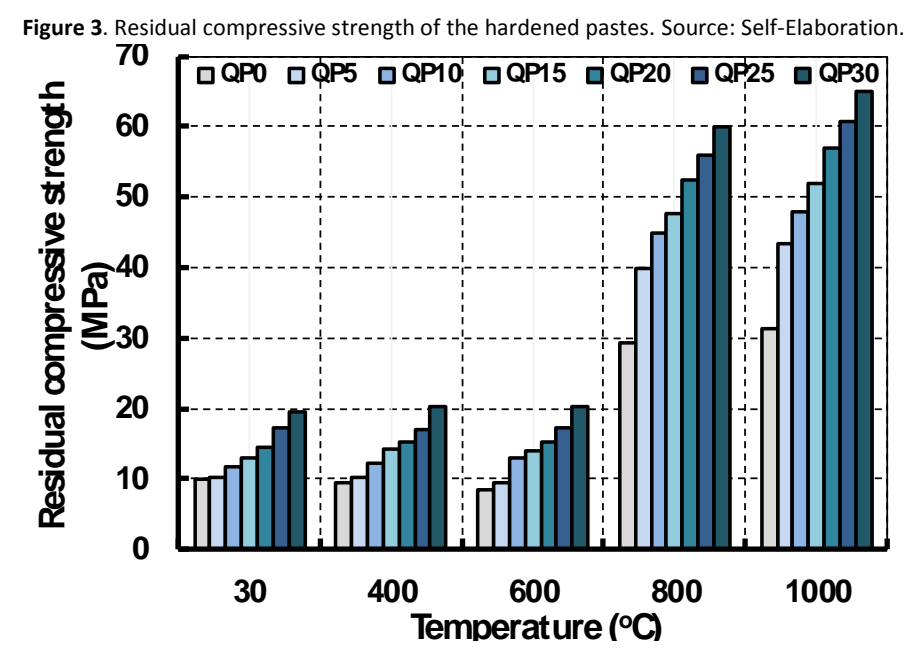

In the literature, there are still contradictory results about the effect of elevated temperatures on AAS matrices. Pan et al. (2018) found a reduction in the compressive strength of AAS pastes activated with sodium metasilicate after exposure to 300 and $600{ }^{\circ} \mathrm{C}$. Kürklü (2016) found a reduction in the compressive strength of AAS mortars activated with $\mathrm{NaOH}$ cured at $60{ }^{\circ} \mathrm{C}$ for $48 \mathrm{~h}$ after exposure to $200-1000{ }^{\circ} \mathrm{C}$. Wang, Wang, \& Lo (2014) found a reduction in the compressive strength of AAS pastes activated with sodium silicate and $\mathrm{NaOH}$ after exposure to 500 and $800{ }^{\circ} \mathrm{C}$. Zuda, Pavlík, Rovnaníková, Bayer, \& Černý (2006) found a reduction in the compressive strength of AAS mortars activated with water glass cured in water bath after exposure to $200-800{ }^{\circ} \mathrm{C}$ for $2 \mathrm{~h}$, but the compressive strength started to increase after exposure to 1000 and $1200{ }^{\circ} \mathrm{C}$. The same trend of the results was obtained for AAS pastes activated with sodium silicate cured in water bath after exposure to elevated temperatures (Rovnaník, Bayer, \& Rovnaníková, 2013).

Zuda et al. (2010) found a reduction in the compressive strength of AAS lightweight materials containing electrical porcelain and expanded vermiculite activated with dried sodium silicate cured in water bath after exposure to 200$1000{ }^{\circ} \mathrm{C}$ for $2 \mathrm{~h}$. On the other hand, a significant increase in the compressive strength was observed at $1200{ }^{\circ} \mathrm{C}$. (Guerrieri, Sanjayan, \& Collins, 2009) found a reduction in the compressive strength of AAS concretes activated with sodium metasilicate cured at $23{ }^{\circ} \mathrm{C}$ in a saturated lime bath after exposure to $100-1200{ }^{\circ} \mathrm{C}$. Türker, Balçikanli, Durmuş, Özbay, \& Erdemir (2016) found a reduction in the compressive strength of AAS mortars activated with a solution of sodium silicate and $\mathrm{NaOH}$ cured at $60{ }^{\circ} \mathrm{C}$ for $6 \mathrm{~h}$ then at laboratory conditions after exposure to $200-800{ }^{\circ} \mathrm{C}$ for $2 \mathrm{~h}$. On the other hand, mortars cured at ambient temperatures exhibited higher compressive strength after exposure to 200 and $400{ }^{\circ} \mathrm{C}$, compared to the control, whilst a reduction in the strength was obtained after exposure to 600 and 800 ${ }^{\circ} \mathrm{C}$. Rashad et al. (2016) found an enhancement in the compressive strength of AAS pastes activated with $\mathrm{Na}_{2} \mathrm{SO}_{4}$ after exposure to $200-600{ }^{\circ} \mathrm{C}$, whilst exposure to $800{ }^{\circ} \mathrm{C}$ decreased it. Nasr, Pakshir, \& Ghayour, (2018) found an enhancement in the compressive strength of AAS mortars, cured at ambient temperature, activated with $2 \% \mathrm{Na}_{2} \mathrm{O}$ after exposure to $200-600{ }^{\circ} \mathrm{C}$. Other studies found higher compressive strength of slag activated with $\mathrm{Na}_{2} \mathrm{SO}_{4}$ after exposure to $200-600{ }^{\circ} \mathrm{C}$ (Rashad et al., 2012). From the previous discussions, it can be concluded that the behaviour of AAS system under thermal loads could be affected by many factors such as curing conditions (Nasr et al., 2018; Türker et al., 2016), activator type (Cheng \& Chiu, 2003) and activator concentrations (Nasr et al., 2018; Rashad et al., 2012; Rashad et al., 2016).

On the theme of alkali-activated slag/QP, it was noticed that the tendency of these mixtures under the effect of elevated temperatures were analogous to those of the pure AAS pastes, of which a slight reduction in the residual compressive strength was obtained at 400 and $600{ }^{\circ} \mathrm{C}$, then a significant enhancement was obtained at 800 and 1000 ${ }^{\circ} \mathrm{C}$. The initial compressive strength of QP5 was enhanced by 3.88 and 4.21 times greater after exposure to 800 and $1000{ }^{\circ} \mathrm{C}$, whilst those containing 30\% QP (QP30) was enhanced by 3.1 and 3.33 times greater. As can be seen from Fig. 3 , the residual strength increased with increasing the QP content. The incorporation of $5 \%$ QP enhanced the residual compressive strength by $6.72 \%, 10.29 \%, 36.75 \%$ and $38.8 \%$ after exposure to $400,600,800$ and $1000{ }^{\circ} \mathrm{C}$, respectively, whilst the incorporation of 30\% QP enhanced it by $112 \%, 138.2 \%, 104.7 \%$ and $108.1 \%$, respectively, in comparison with their counterparts without QP. A logical reason for enhancing compressive strength before and after exposure to elevated temperatures is that QP particles could act as micro-aggregates that can eliminate the higher shrinkage and 
propagate the cracks that AAS pastes ache. Furthermore, during heating, the water could be evaporated from the specimens causing steam pressure that can alter the crystalline phase of QP to amorphous silica. In addition, QP ( $\beta$ cristobalite) has a high melting point $\left(11711^{\circ} \mathrm{C}\right)$ which enables it to resist high temperatures. It is worth mentioning that the incorporation of QP not only increased the thermal resistance of AAS pastes but also increased the thermal resistance of conventional PC pastes (Rashad, 2018a).

\section{X-ray diffraction}

Figures 4-6 illustrates the XRD patterns of selected samples before and after subjecting to elevated temperatures. Figure 4 illustrates the XRD patterns of QP0, QP5, QP10, QP15, QP20, QP25 and QP30 after 28 days of hydration. There is an implication of the amorphous phase of CSH gel confirmed by existing a broad hump in the region of $25^{\circ}$ and $35^{\circ} 2 \theta$. This hump slightly increased with increasing QP content implying higher geopolymerization which leading to higher compressive strength. The semi-crystalline $\mathrm{CSH}(\mathrm{I})\left(\mathrm{CaO} \cdot \mathrm{SiO}_{2} \cdot \mathrm{nH}_{2} \mathrm{O}\right)$ overlaps with calcite $\left(\mathrm{CaCO}_{3}\right)$ can be detected. Minor peaks of gehlenite $\left(\mathrm{Ca}_{2} \mathrm{Al}\left(\mathrm{Al}\left(\mathrm{AlSiO} \mathrm{O}_{7}\right)\right)\right.$, calcite, akermanite $\left(\mathrm{Ca}_{2} \mathrm{Mg}\left(\mathrm{S}_{i} \mathrm{O}_{7}\right)\right)$, merwinite $\left(\mathrm{Ca}_{3} \mathrm{Mg}(\mathrm{SiO})_{2}\right)$ and hydrotalcite $\left(\mathrm{Mg}_{6} \mathrm{Al}_{2} \mathrm{CO}_{3}(\mathrm{OH})_{16} .4 \mathrm{H}_{2} \mathrm{O}\right)$ can be distinguished. The incorporation of QP into AAS pastes presented predominate peaks of the crystalline phase of quartz $\left(\mathrm{SiO}_{2}\right)$. The intensity of this phase increased with increasing $Q P$ content.

Figure 5 illustrates the XRD patterns of the samples prepared with pure slag (QPO) before and after being exposed to 400,800 and $1000{ }^{\circ} \mathrm{C}$. No essential change on the XRD of QPO samples after exposure to elevated temperatures was observed in comparison with their counterparts before heating. On the other hand, the peak identifications after heating at 800 and $1000{ }^{\circ} \mathrm{C}$ exhibited major changes in the phase compositions. The peaks of akermanite dramatically increased with increasing temperatures. The crystallization of akermanite can occur at approximately $710{ }^{\circ} \mathrm{C}$ (Rovnaník et al., 2013). The formation and growth of akermanite peaks due to elevated temperatures have very important consequences for its practical use. It was reported that akermanite is a mineral with a melting temperature $>1450{ }^{\circ} \mathrm{C}$ (Wu \& Chang, 2006). It has very high thermal stability (Zuda, Rovnaník, Bayer, \& Černý, 2008). Therefore, the compressive strength dramatically increased after exposure to 800 and $1000{ }^{\circ} \mathrm{C}$. Minor crystalline phases of merwinite and gehlenite were detected. Figure 6 illustrates the XRD patterns of the samples prepared with AAS containing 30\% QP (QP30) before and after being exposed to 800 and $1000{ }^{\circ} \mathrm{C}$. Similar peaks of akermanite, merwinite and gehlenite to those presented in Figure 5 were detected. Peaks of quartz $\left(\mathrm{SiO}_{2}\right)$ can be observed. The intensities of these peaks were decreased with increasing temperatures, meanwhile, the crystalline phase of quartz was decreased by elevated temperatures.

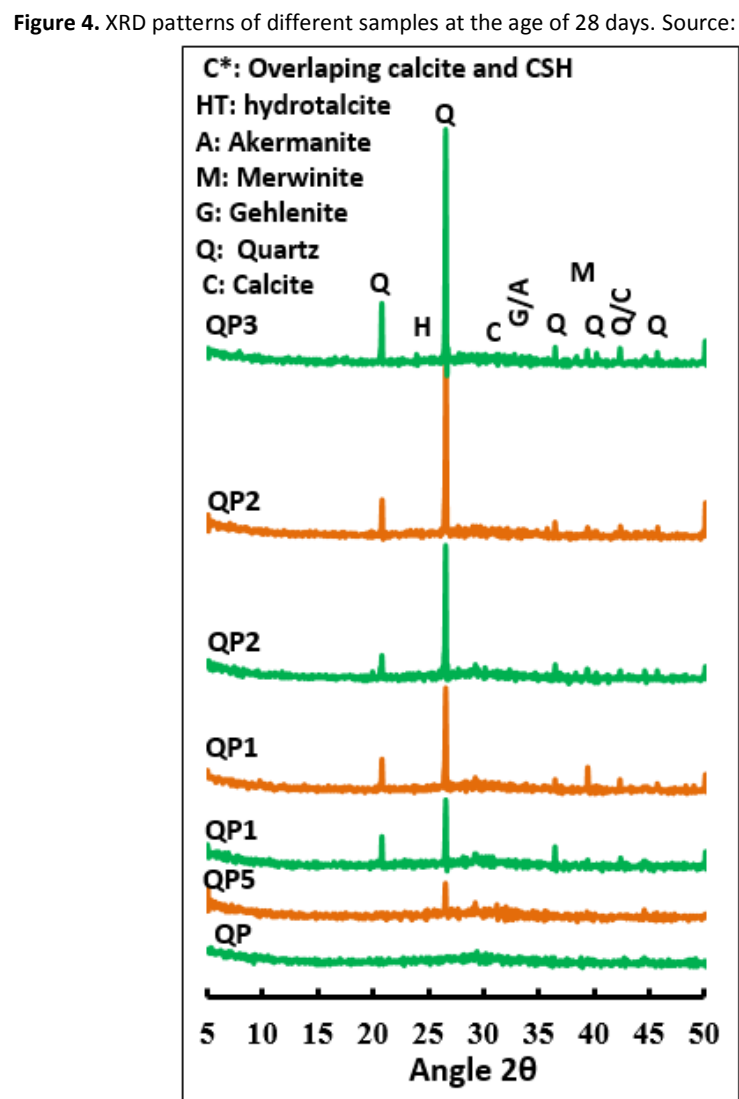



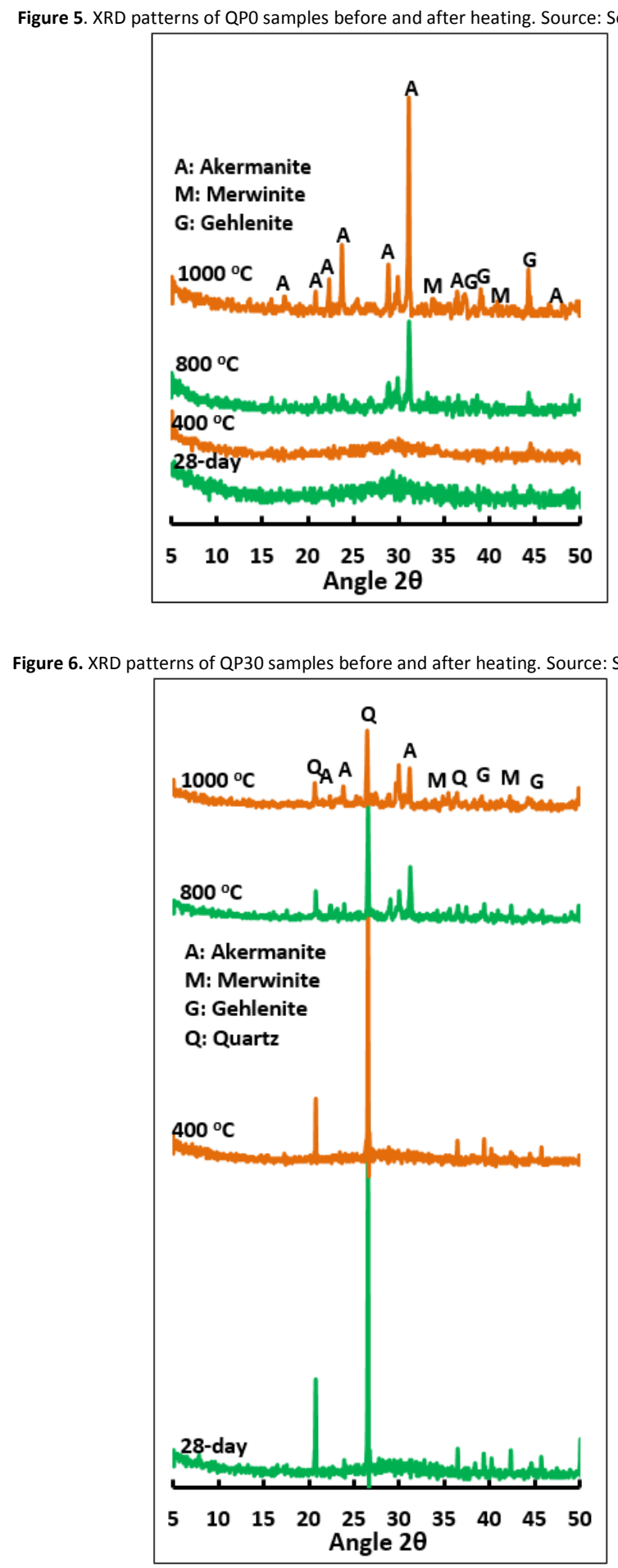

\section{Thermogravimetric analysis}

TGA and its derivative (DTG) are used to determine the water evaporation rates in a system or determine the mechanism by which a material loses weight as a result of controlled heating. In the current investigation, the weight loss and its derivative curves in the range of $30-1000{ }^{\circ} \mathrm{C}$ for both QPO and QP30 samples are illustrated in Figures 7 and 8. The foremost DTG endothermic peak located at approximately 90-100 is associated with the evaporation of the free water and the loss of water molecules leading to dehydration of CSH (I) gel presented in the binders. The endothermic peak identified around $680{ }^{\circ} \mathrm{C}$ is attributed to the decomposition of carbonates. It can be noted that the main endothermic peak of QP30 sample is larger than those of QPO sample, meanwhile that the amount of CSH (I) in this sample is higher than the control. Thus, the higher compressive strength of QP30 over those of QP0 was obtained. 


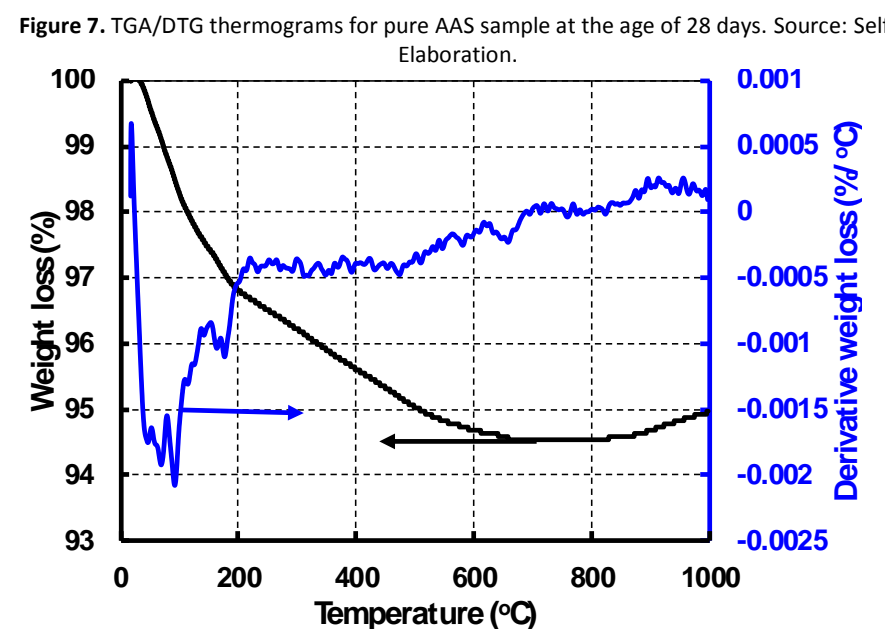

Figure 8. TGA/DTG thermograms for the sample containing $30 \%$ QP at the age of 28 days. Source: Self-

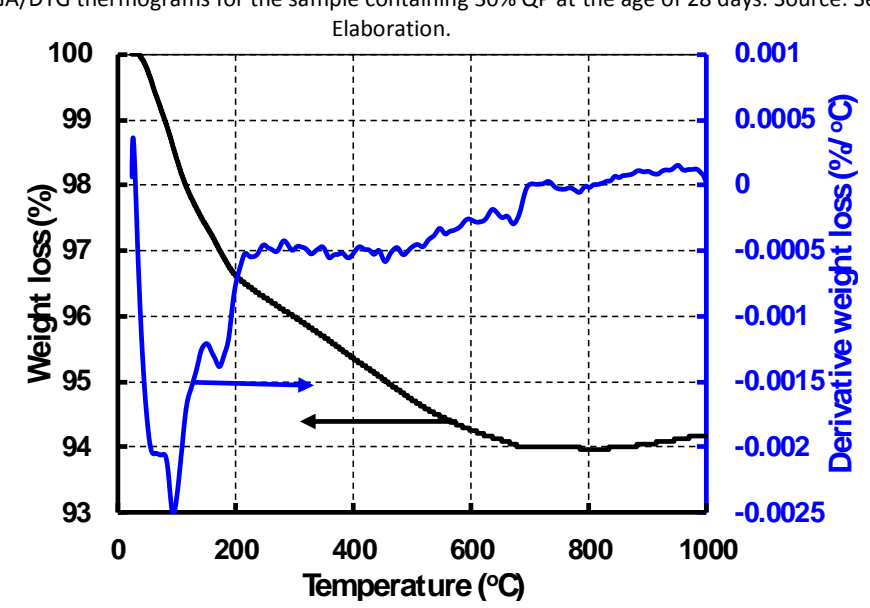

\section{Microstructural analysis}

Figure 9 illustrates SEM micrographs of fracture of the hardened QPO and QP30 samples after curing for 28 days. It can be noted that the microstructure of the sample prepared from pure slag dominated with a lot of unreacted and partially reacted slag particles visible as irregular jagged particles. The more slag grains of larger size were observed. Through these particles, there are a lot of disconnected pores with a limited amount of CSH. Replacing slag with 30\% QP led to a significant reduction in the pores, a reduction in the slag grains size, a reduction in the number of unreacted and partially reacted slag particles and more amount of CSH. These resulted in a denser and more compacted microstructure which led to higher compressive strength.

Figure 10 illustrated SEM micrographs of fracture of hardened QP0 and QP30 samples after being exposed to 400, 800 and $1000{ }^{\circ} \mathrm{C}$. No essential change in the microstructure for the QPO and QP30 samples after exposure to $400{ }^{\circ} \mathrm{C}$ was observed in comparison with their counterparts before heating. This confirms the slight change in the compressive strength of the pastes being exposed to $400{ }^{\circ} \mathrm{C}$ to their references. On the other hand, an essential change in the microstructure of both QP0 and QP30 samples was observed after exposure to 800 and $1000{ }^{\circ} \mathrm{C}$. A new binder phase based on akermanite, which has high thermal stability, was observed. This phase was already proven in the XRD analysis illustrated in Figures 5,6. The microstructure of QP30 samples after exposure to 800 and 1000 still denser and more compact than their counterparts without QP. This confirms the higher residual strength of QP30 over those of QPO. Exposing samples to 800 and $1000{ }^{\circ} \mathrm{C}$ led to sintering reaction and demolish the un-reacted and partially reacted slag particles. Consequently, higher compressive strength was obtained. Despite there are some pores in the microstructure of both QP0 and QP30 after exposure to 800 and $1000{ }^{\circ} \mathrm{C}$ due to the sintering process, the compressive strength was increased. These findings match with the hypothesis of Dias, Khoury, \& Sullivan (1990) i.e. the increase in strength was also in the bonding properties of hydrates (a larger compressive strength was obtained for a larger porosity of the material). 

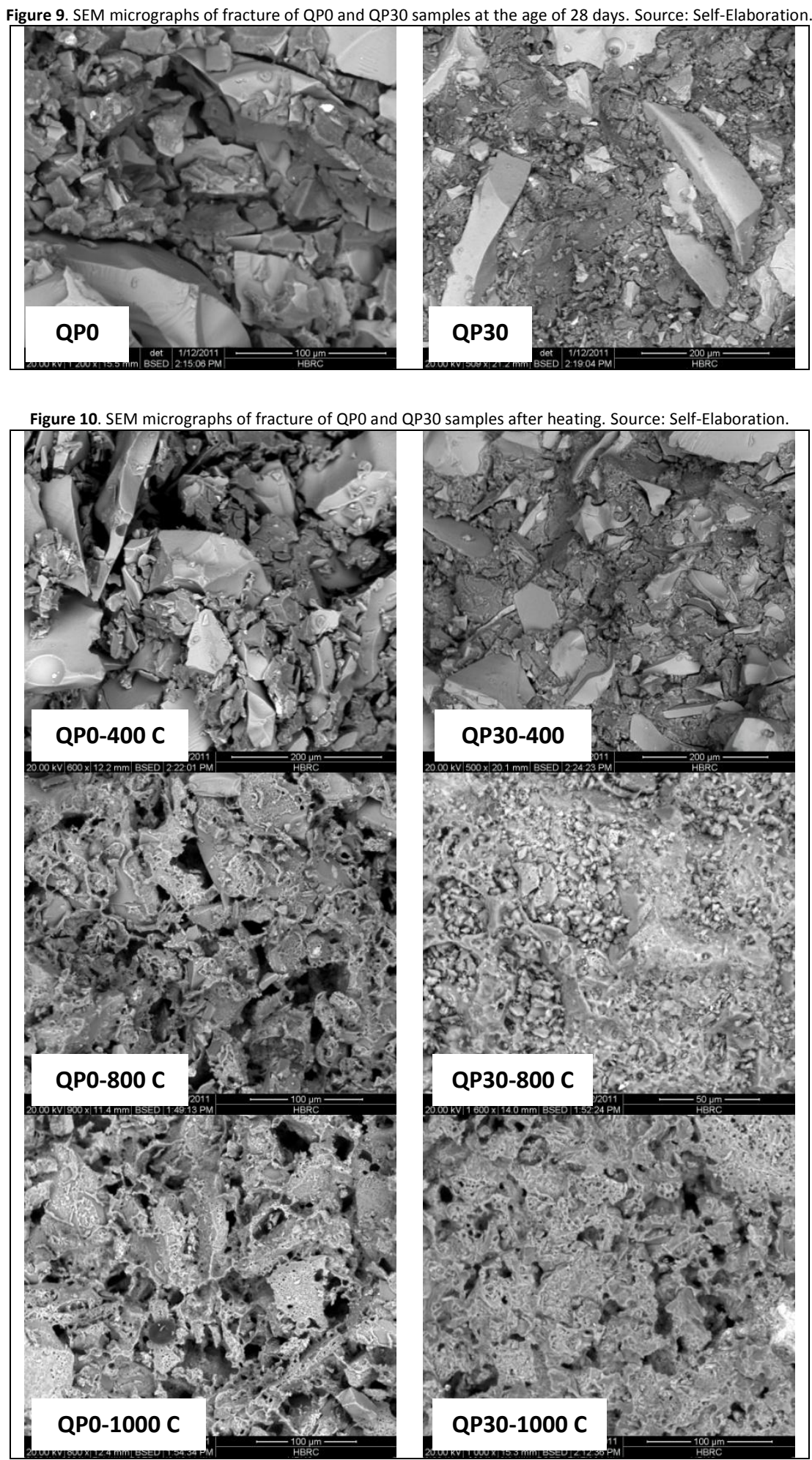

Conclusions

In this work, the slag in AAS pastes activated with sodium silicate was partially replaced with $5-30 \%$ QP, by weight. The compressive strength values before and after exposure to $400-1000{ }^{\circ} \mathrm{C}$ have been measured. The formed phases were investigated using XRD and TGA/DTG. The microstructure of selected samples was analyzed by SEM. The main findings of this study are: 
- The compressive strength of the pastes increased with increasing QP content due to the filling effect of QP. The initial compressive strength of pure AAS paste was increased by $97.3 \%$ with the incorporation of $30 \%$ QP.

- No essential change in the initial compressive strength of the pastes was observed after being exposed to 400 and $600^{\circ} \mathrm{C}$.

- The residual strength of all hardened pastes was significantly increased after being exposed to 800 and $1000{ }^{\circ} \mathrm{C}$ due to sintering and formation of akermanite.

- The residual compressive strength of the hardened pastes increased with increasing QP content. The incorporation of $5 \%$ QP increased the residual compressive strength by $6.72,10.29 \%, 36.75 \%$ and $38.8 \%$ after firing at 400,600 , 800 and $1000{ }^{\circ} \mathrm{C}$, whilst $30 \%$ QP increased it by $112 \%, 138.2 \%, 104.7 \%$ and $108.1 \%$, respectively.

- In a word, QP can be used to enhance the compressive strength of AAS pastes before and after being subjected to elevated temperatures.

\section{References}

Cheng, T.-W., \& Chiu, J. (2003). Fire-resistant geopolymer produced by granulated blast furnace slag. Minerals Engineering, 16(3), 205-210.

Davidovits, J. (1994). Global warming impact on the cement and aggregates industries. World resource review, 6(2), 263-278.

Dias, W., Khoury, G., \& Sullivan, P. (1990). Mechanical properties of hardened cement paste exposed to temperatures up to $700 \mathrm{C}(1292 \mathrm{~F})$. Materials Journal, 87(2), 160-166.

Guerrieri, M., Sanjayan, J., \& Collins, F. (2009). Residual compressive behavior of alkali-activated concrete exposed to elevated temperatures. Fire and Materials: An International Journal, 33(1), 51-62.

Kürklü, G. (2016). The effect of high temperature on the design of blast furnace slag and coarse fly ash-based geopolymer mortar. Composites part b: engineering, 92, 9-18.

Nasr, D., Pakshir, A. H., \& Ghayour, H. (2018). The influence of curing conditions and alkaline activator concentration on elevated temperature behavior of alkali activated slag (AAS) mortars. Construction and Building Materials, 190, 108-119.

Nguyen, T. T., Bui, H. H., Ngo, T. D., Nguyen, G. D., Kreher, M. U., \& Darve, F. (2019). A micromechanical investigation for the effects of pore size and its distribution on geopolymer foam concrete under uniaxial compression. Engineering Fracture Mechanics, 209, 228-244.

Pan, Z., Tao, Z., Cao, Y., Wuhrer, R., \& Murphy, T. (2018). Compressive strength and microstructure of alkali-activated fly ash/slag binders at high temperature. Cement and Concrete Composites, 86, 9-18.

Rashad, A., Bai, Y., Basheer, P., Collier, N., \& Milestone, N. (2012). Chemical and mechanical stability of sodium sulfate activated slag after exposure to elevated temperature. Cement and Concrete Research, 42(2), 333-343.

Rashad, A. M. (2015). Influence of different additives on the properties of sodium sulfate activated slag. Construction and Building Materials, 79 , 379-389.

Rashad, A. M. (2018a). Effect of quartz-powder on the properties of conventional cementitious materials and geopolymers. Materials Science and Technology, 34(17), 2043-2056.

Rashad, A. M. (2018b). An overview on rheology, mechanical properties and durability of high-volume slag used as a cement replacement in paste, mortar and concrete. Construction and Building Materials, 187, 89-117.

Rashad, A. M., Zeedan, S. R., \& Hassan, A. A. (2016). Influence of the activator concentration of sodium silicate on the thermal properties of alkaliactivated slag pastes. Construction and Building Materials, 102, 811-820.

Rovnaník, P., Bayer, P., \& Rovnaníková, P. (2013). Characterization of alkali activated slag paste after exposure to high temperatures. Construction and Building Materials, 47, 1479-1487.

Türker, H. T., Balçikanli, M., Durmuş, I. H., Özbay, E., \& Erdemir, M. (2016). Microstructural alteration of alkali activated slag mortars depend on exposed high temperature level. Construction and Building Materials, 104, 169-180.

Vaičiukynienè, D., Nizevičienė, D., Kielè, A., Janavičius, E., \& Pupeikis, D. (2018). Effect of phosphogypsum on the stability upon firing treatment of alkali-activated slag. Construction and Building Materials, 184, 485-491.

Wang, W.-C., Wang, H.-Y., \& Lo, M.-H. (2014). The engineering properties of alkali-activated slag pastes exposed to high temperatures. Construction and Building Materials, 68, 409-415.

Wu, C., \& Chang, J. (2006). A novel akermanite bioceramic: preparation and characteristics. Journal of biomaterials applications, 21(2), 119-129.

Zuda, L., Drchalová, J., Rovnaník, P., Bayer, P., Keršner, Z., \& Černý, R. (2010). Alkali-activated aluminosilicate composite with heat-resistant lightweight aggregates exposed to high temperatures: Mechanical and water transport properties. Cement and Concrete Composites, 32(2), 157-163.

Zuda, L., Pavlík, Z., Rovnaníková, P., Bayer, P., \& Černý, R. (2006). Properties of alkali activated aluminosilicate material after thermal load. International Journal of Thermophysics, 27(4), 1250-1263.

Zuda, L., Rovnaník, P., Bayer, P., \& Černý, R. (2008). Effect of high temperatures on the properties of alkali activated aluminosilicate with electrical porcelain filler. International Journal of Thermophysics, 29(2), 693-705. 